\title{
N-Amino-imidazol-2-one (Nai) Residues as Tools for Peptide Mimicry: Synthesis, Conformational Analysis and Biomedical Applications
}

\author{
Yousra Hamdane \\ Julien Poupart \\ William D. Lubell* \\ Département de Chimie, Université de Montréal, \\ Succursale Centre-Ville, Montréal, QC H3C3]7, Canada \\ William.lubell@umontreal.ca \\ In memory of Professor Robin E. Offord (1940-2021), inspirational \\ scholar, peptide scientist, humanitarian and mentor dedicated to \\ the empowerment of young investigators.
}

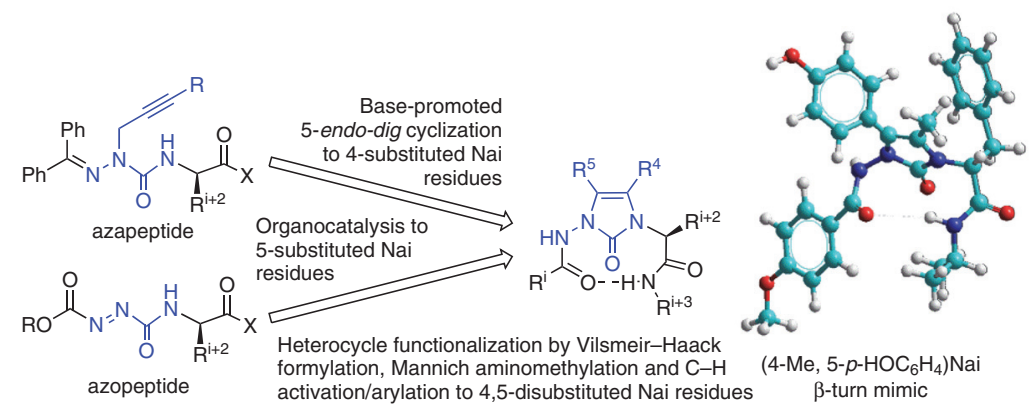

Received: 23.07 .2021

Accepted after revision: 17.09.2021

Published online: 05.01 .2022

DOI: 10.1055/s-0040-1719862; Art ID: ss-2021-z0438-sr

License terms: (c)

(c) 2022. The Author(s). This is an open access article published by Thieme under the terms of the Creative Commons Attribution-NonDerivative-NonCommercial-License, permitting copying and reproduction so long as the original work is given appropriate credit. Contents may not be used for commercial purposes or adapted, remixed, transformed or built upon. (https://creativecommons.org/licenses/by-nc-nd/4.0/)

Abstract N-Amino-imidazol-2-one (Nai) residues are tools for studying peptide-backbone and side-chain conformation and function. Recent methods for substituted Nai residue synthesis, conformational analysis by X-ray crystallography and computation, and biomedical applications are reviewed, demonstrating the utility of this constrained residue to favor biologically active turn conformers with defined $x$-dihedral angle orientations.

1 Introduction

2 Synthetic Methods

3 Conformational Analysis

4 Biomedical Applications

5 Conclusions

Key words $\mathrm{N}$-aminoimidazol-2-one, Nai residue, peptide mimicry, 5 endo-dig cyclization, $\beta$-turn, organocatalysis, cluster of differentiation36 (CD36)

\section{Introduction}

Tools for peptide mimicry offer means to improve potency, selectivity and pharmacokinetic properties, which may limit the applications of natural counterparts in medicine. ${ }^{1-3}$ Peptide mimic scaffolds which restrict backbone and side-chain topology to specific secondary structures, such as $\beta$-turns $\mathbf{1}$, are especially valuable for furnishing aca- demic understanding of the conformational requirements for activity (e.g., 2-5) (Figure 1). ${ }^{4,5}$ Synthetic methods for the effective installation of a variety of such frameworks at different points along the peptide sequence are desirable for systematic exploration of structure-activity relationships to discern active pharmacophores. ${ }^{6}$

$\mathrm{N}$-Amino-imidazol-2-one and -imidazolidin-2-one [Nai (4) and Aid (5)] residues are dipeptide surrogates with strong potential for peptide-based drug discovery.,7-13 Combining the stereo-electronic features of azapeptides (2) with the covalent constraint characteristic of $\alpha$-amino- $\gamma$ lactam [Agl, Freidinger-Veber lactam (3)] residues, ${ }^{14-16}$ Aid and Nai peptides can replicate natural secondary structures by adopting defined backbone and side-chain geometry. ${ }^{4}$ Lone pair-lone pair repulsion between the adjacent nitrogen of the $\mathrm{N}$-acyl semicarbazide component of Aid and Nai residues constricts rotation about the $\varphi$-dihedral angle. ${ }^{4,14,15}$ The five-membered cyclic urea in Aid and Nai residues restricts rotation about the backbone $\psi$ - and $\omega$-dihedral angles. ${ }^{4,16}$
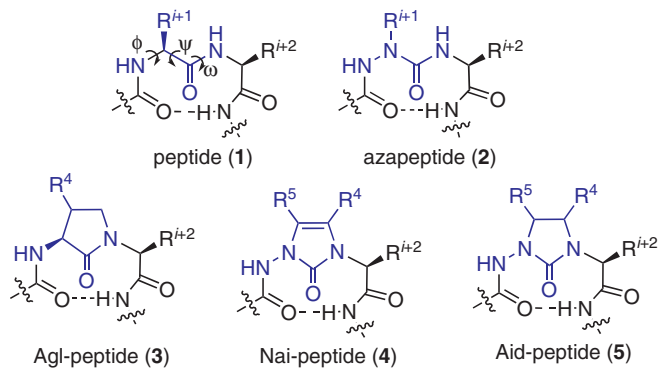

Figure 1 Strategies to constrain backbone and side-chain geometries of amino acid residues in peptides. Amino amide and surrogates depicted in blue situated at the $i+1$ residue of a $\beta$-turn conformer. 


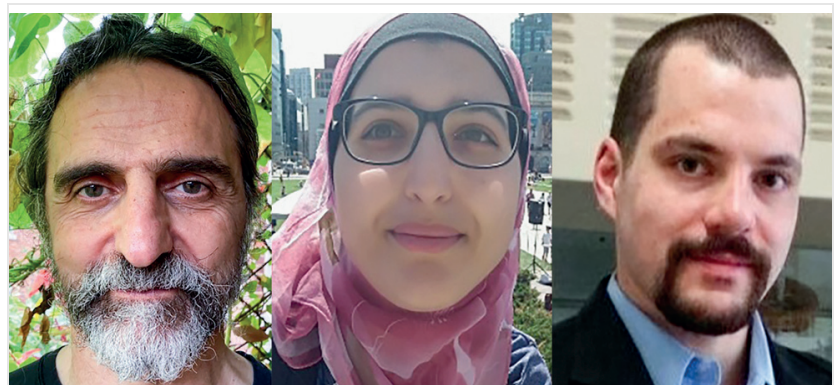

William D. Lubell (left) is a medicinal chemist and peptide scientist who employs peptide and peptidomimetic prototypes to target and modulate biologically relevant receptors for drug discovery (www.wdlubellgroup.com). After receiving B.A. (Columbia College, 1984) and Ph.D. (University of California, Berkeley, 1989, with Professor Henry Rapoport) degrees, Lubell was a Japan Society for the Promotion of Science Fellow (1990-1991) in the laboratory of Professor Ryoji Noyori at Nagoya University, Japan, before joining the Department of Chemistry at the Université de Montréal in 1991. Studying novel approaches for educating and performing organic chemistry research in academia, Lubell is a co-author of $>250$ scientific publications, a recipient of the Canadian Society for Chemistry Bernard Belleau (2013) and Teva Canada Limited Biological and Medicinal Chemistry Lectureship (2018) Awards for seminal achievements in bio-medicinal chemistry, and an originator of Molecules of Life (www.moleculesoflife.ca), which explores experiential educational techniques to teach elementary school students about molecules.

Yousra Hamdane (center) received her B.Sc. (2019) and M.Sc. (2020) degrees in chemistry from the Université de Montréal, before promotion to the Ph.D. program. Performing graduate studies under the direction of Professor William Lubell, she is currently exploring the application of $\mathrm{N}$-aminoimidazolones in the study of cluster of differentiation-36 (CD36) ligands.

Julien Poupart (right) received his B.Sc. (2012), M.Sc. (2014) and Ph.D. (2020) degrees in chemistry from the Université de Montréal, where he was an Outstanding Teaching Assistant Award recipient in 2019. Upon completion of his graduate studies under the direction of Professor William Lubell, he received Dean's list distinction for his Ph.D. dissertation on 4,5-disubstituted $\mathrm{N}$-aminoimidazolones. An Entrepreneurship in Oncology Scholar (2020), he joined the laboratory of Dr. Anne Marinier as a postdoctoral research fellow in medicinal chemistry (2020-2021, in collaboration with Professor Sylvie Mader) at the Institute for Research in Immunology and Cancer (IRIC), where he is currently a research advisor applying bio-organic and medicinal chemistry approaches in cancer research, and developing DNA-encoded chemical libraries for early drug discovery and development.

The ability of the Nai residue to serve in a constrained peptide with restricted backbone dihedral angles is enhanced by capacity to add to the 4- and 5-positions of the heterocycle ring, substituents, which may mimic the functionality and orientation of amino acid side chains (Figure 2). ${ }^{4,7-11}$ In peptides, the energetically favored rotational isomers position the amine and the side-chain functional group anti-periplanar $\left(180^{\circ}\right)$ in so-called trans $\chi^{1}$-space or in gauche $\left( \pm 60^{\circ}\right)$ orientations. ${ }^{17-19}$ Substituents at the 4-position of the Nai heterocycle are oriented in trans $x$ space. ${ }^{4,7,11}$ On the other hand, Nai ring substituents at the 5position may adopt flattened versions of the gauche $\chi$-space contingent on nitrogen hybridization and ring puckering. ${ }^{8}$ In sum, Nai residues and Aid counterparts impart constraints that can promote conformers such as turn structures which are favored for molecular recognition. ${ }^{20}$

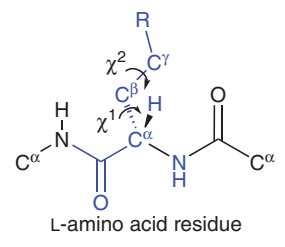

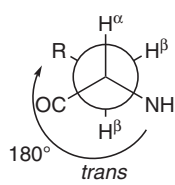

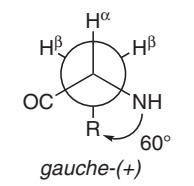

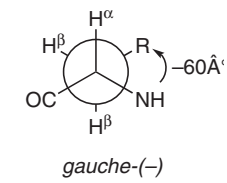

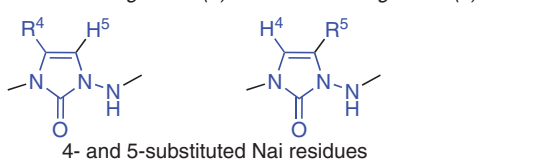
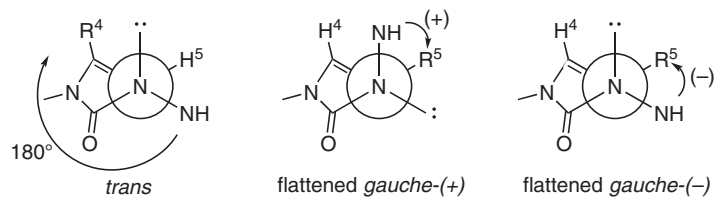

Figure 2 The trans and gauche side-chain conformations in $x$-space of an amino acid residue may be respectively replicated by 4 - and 5 -substituted Nai residues

The chemistry of Nai and Aid residues was reviewed in 2017. ${ }^{4}$ Several innovations have since been introduced for the preparation of Nai analogues possessing different substituents at the 4 - and 5-positions. ${ }^{7-10}$ This short review provides an overview of the recent synthetic methods, conformational analysis and biomedical applications of Nai analogues.

\section{Synthetic Methods}

4-Substituted Nai analogues have been synthesized from aza-propargylglycine (azaPra) dipeptides by way of an apparent 5-exo-dig cyclization followed by alkene internalization (Scheme 1).,7 Alkylation of semicarbazone 6 with propargyl bromide provided azaPra peptide 7 , which underwent base-promoted cyclization using sodium hydride in acetonitrile to afford exocyclic olefin $\mathbf{8}$ that isomerized spontaneously upon standing overnight to give the more thermodynamically stable endocyclic 4-methyl Nai dipeptide 9. ${ }^{7}$ Olefin migration was catalyzed by acid under conditions such as silica gel chromatography and ester solvolysis with trifluoroacetic acid. ${ }^{7}$ A combination of excess $\mathrm{NaH}$ in acetonitrile was necessary to achieve high yields of cyclization which were unaffected by gold catalysis.? 

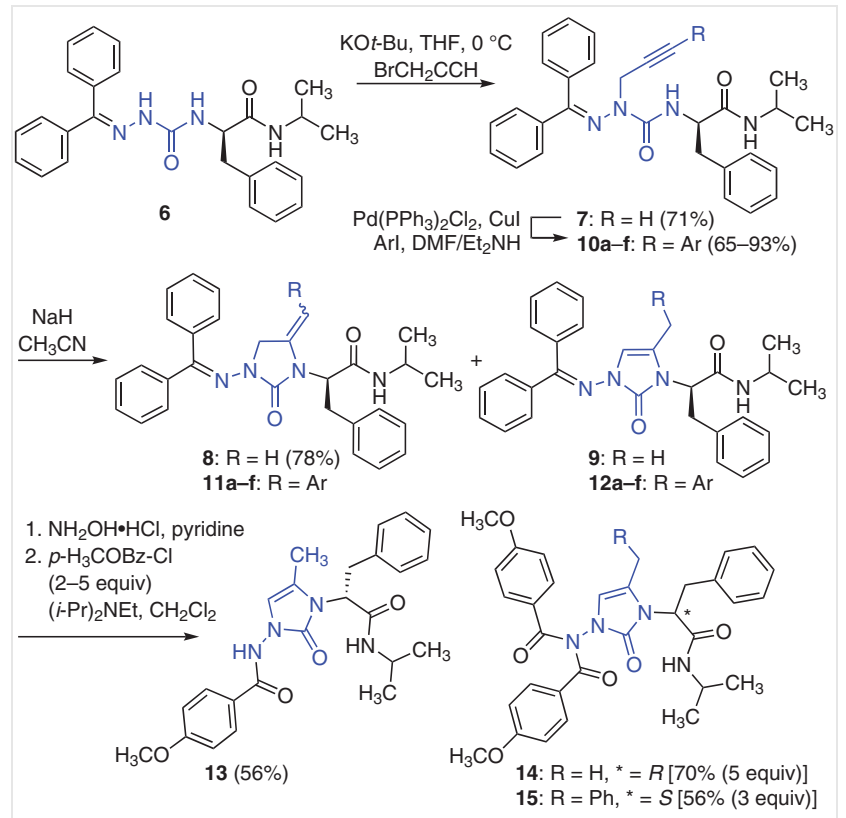

Scheme 1 4-Substituted Nai dipeptide synthesis

Diversification of the 4-position substituent was achieved using Sonogashira coupling conditions. ${ }^{7}$ A number of electron-rich and electron-poor aryl and heteroaryl substituents were efficiently introduced at the terminal alkyne position in $65-93 \%$ yields. ${ }^{7}$ Base-promoted cyclization afforded predominantly exocyclic alkenes 11a-f, which were converted into the 4-substituted Nai dipeptides 12a-f on exposure to acidic conditions (Figure 3). For subsequent conformational analyses to be discussed later, $\mathrm{N}$-acyl Nai dipeptide amides 13-15 were prepared after benzhydrylidene removal under transimination conditions using hydroxylamine hydrochloride in pyridine, ${ }^{21,22}$ and acylation of the resulting semicarbazide with different amounts of $p$ methoxybenzoyl chloride. ${ }^{7,11}$

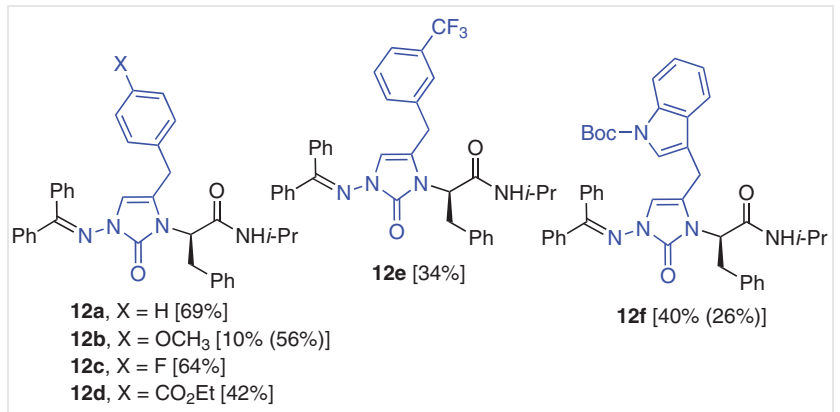

Figure 3 4-Arylmethyl-substituted Nai cyclization products [yields $\mathbf{1 1}+12$ (recovered starting material)]

In contrast to reactions on $C$-terminal amides $\mathbf{7}$ and $\mathbf{1 0}$, the sodium hydride cyclization conditions gave epimerization of $C$-terminal ester counterparts (e.g., 16) (Scheme
2) ${ }^{7,9}$ Noting that deprotonation of the primary amide by sodium hydride could inhibit $\alpha$-proton removal and epimerization under the alkaline conditions, ${ }^{7}$ alternative cyclization conditions and protection of the dipeptide were explored to enable subsequent $C$-terminal elongation. ${ }^{9} \mathrm{Cy}-$ clization was affected using potassium tert-butoxide as a milder base than sodium hydride in dry THF. ${ }^{9,23,24}$ Although epimerization remained significant using azaPra dipeptide ester 16, acid counterpart 18 could be cyclized by a treatment with $t$-BuOK in THF to provide Nai dipeptide acid $\mathbf{1 9}$ in 60\% yield and a $98: 2$ enantiomeric ratio (er) (Scheme 2). ${ }^{9}$ Moreover, $N^{\prime}$-Boc-hydrazide $\mathbf{2 0}$ was successfully converted into the Nai dipeptide $\mathbf{2 1}$ in 96\% yield and 96:4 er after treatment under the same conditions. ${ }^{9}$ The enantiomeric purities of ester 17, acid $\mathbf{1 9}$ and hydrazide $\mathbf{2 1}$ were respectively determined after conversion into the corresponding isopropyl amide $\mathbf{9}$, which was analyzed using supercritical fluid chromatography (SFC) on a chiral column. ${ }^{25}$ Amide formation with hydrazide $\mathbf{2 1}$ was performed by way of the corresponding acyl azide, which was generated after Boc group removal with trifluoroacetic acid, oxidation with tert-butyl nitrite, ${ }^{26}$ and then coupling to iso-propylamine in the presence of 1-hydroxy-7-azabenzotriazole (HOAt). ${ }^{9}$

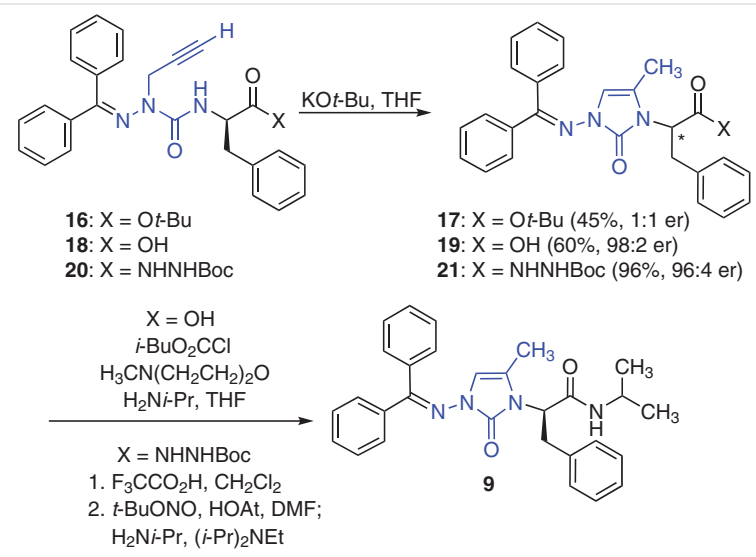

Scheme 2 4-Substituted Nai synthesis using $t$-BuOK conditions

4,5-Disubstituted Nai analogues were prepared by modification of the 5-position of 4-Me-Nai peptides (e.g., 9 and 17). ${ }^{8,9}$ For example, palladium-catalyzed $\mathrm{C}-\mathrm{H}$ activation was used to install various aryl 5-position substituents (Scheme 3). ${ }^{8}$ Aryl iodides and DMSO as the solvent proved essential for cross-coupling, which was best accomplished using $\mathrm{Pd}(\mathrm{OAc})_{2}$ and sodium acetate in the absence of phosphine ligands. ${ }^{8}$ Arylations of ordinary imidazol-2-ones under similar conditions have been suggested to proceed by way of vinyl proton $\mathrm{C}-\mathrm{H}$ activation. ${ }^{27} \mathrm{~A}$ wide scope of 4methyl-5-aryl Nai peptides, which may be considered as constrained phenylalanine (Phe) residues (e.g., 22a-f, 23g-1 and 24), were made by this method which was influenced by the $N$-terminal protection (Scheme 4$)^{8}{ }^{8}$ 


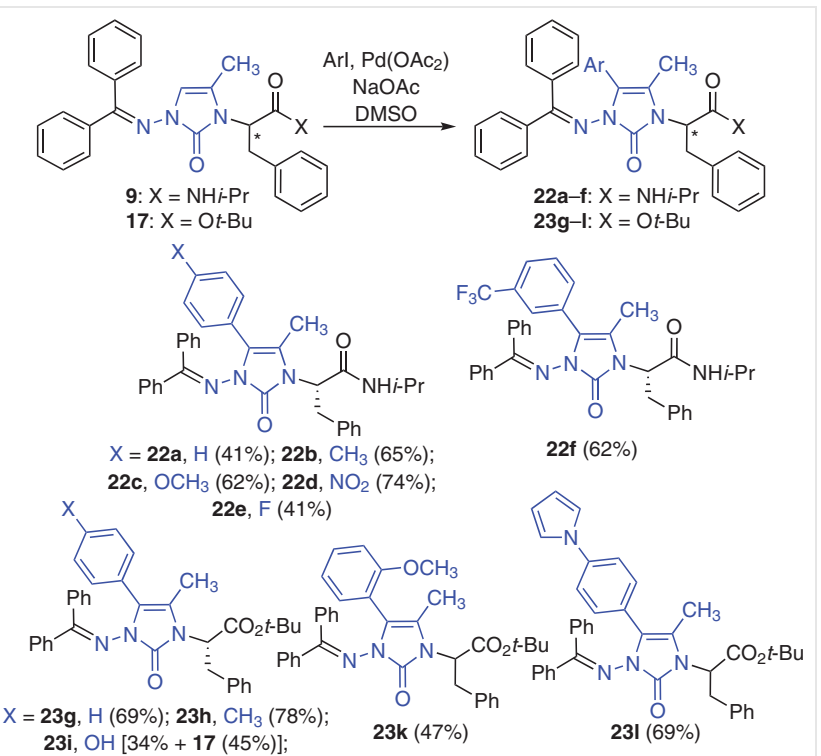

23j, OTs $(80 \%)$

Scheme 3 4-Methyl-5-aryl Nai synthesis by (4-Me)Nai arylation
4-Methyl-5-formyl Nai peptides 25 were prepared using Vilsmeier-Haack conditions (Scheme 5).9,28 The nucleophilic character of the 5-position of Nai peptide $\mathbf{2 1}$ was also illustrated in Mannich aminomethylation chemistry. ${ }^{9,29} 5$ Formyl Nai peptides 25a-d were obtained in 66-81\% yields. A series of conversions of aldehyde $\mathbf{2 5 d}$ was used to obtain other amino acid side chains. For example, 5-carboxylic acid 26 was synthesized by oxidation of aldehyde 25d under Pinnick reaction conditions. ${ }^{9,30}$ Reduction of the aldehyde 25d using sodium borohydride produced alcohol 27. Acid 26 and alcohol 27 may be considered to be constrained aspartic acid (Asp) and homoserine (Hse) derivatives. ${ }^{9}$

Reductive amination of aldehyde 25d gave access to a set of 5-amino methyl Nai analogues 28a-d that may be considered as constrained diaminobutyric acid (Dab) residues. 4-Methyl-5-morpholino methyl Nai 28a was alternatively obtained from hydrazide $\mathbf{2 1}$ by Lewis acid catalyzed Mannich chemistry. ${ }^{8,27}$ Upon exposure to aqueous $\mathrm{HCl}$ $(4 \mathrm{~N})$, 5-morpholino methyl Nai 28a underwent a retroMannich reaction to return the corresponding (4-Me)Nai derivative 21.9,31

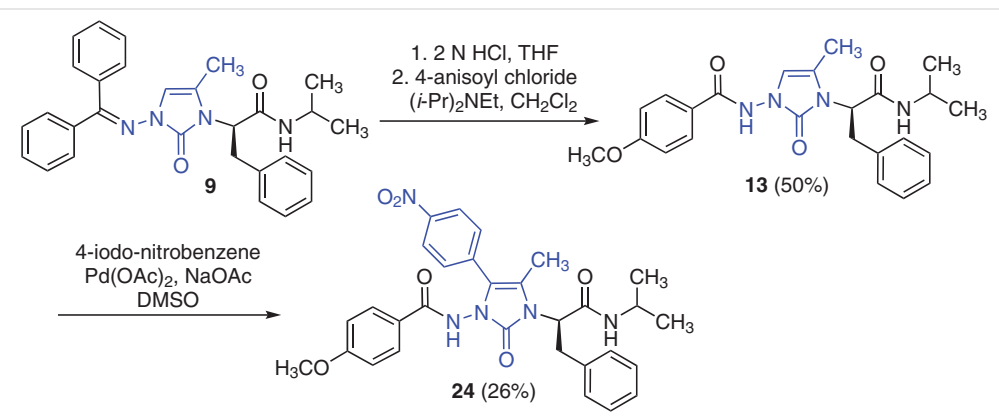

Scheme 4 4-Methyl 5-p-nitrophenyl Nai 24 synthesis

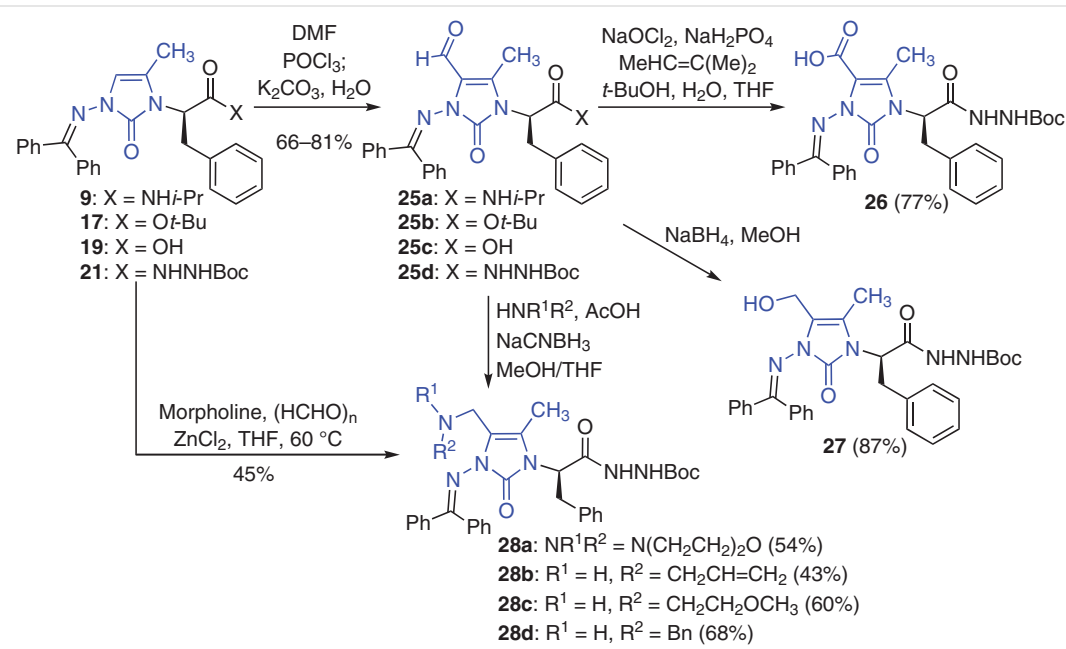

Scheme 5 4-Methyl-5-formyl Nai synthesis and diversification 
5-Substituted Nai analogues were synthesized by an approach featuring the elaboration of azopeptide chemistry (Scheme 6). ${ }^{10,32}$ Azopeptides have been prepared by oxidation of $\mathrm{N}$-protected azaglycine peptides. ${ }^{32}$ Similar to ordinary azodicarboxylates, ${ }^{33,34}$ the azopeptide moiety reacts effectively in pericyclic chemistry. ${ }^{32,35,36}$ For example, DielsAlder and Alder-ene reactions of azopeptides have been used to synthesize aza-pipecolate and aza-allylglycine derivatives, which have been employed to study opioid and cluster of differentiation-36 receptor (CD36) ligands as well as second mitochondria-derived activator of caspase (Smac) mimetics. $32,35,36$

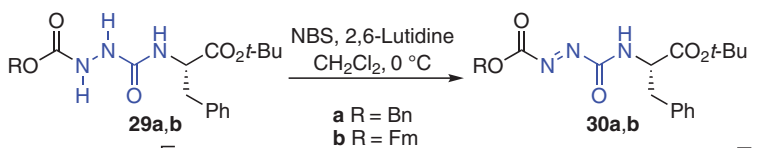

$$
\begin{aligned}
& \stackrel{i-\mathrm{BuCHO}_{2}}{\stackrel{\mathrm{L} \text { - } \mathrm{CH}_{2} \mathrm{Cl}_{2}}{\longrightarrow}}
\end{aligned}
$$

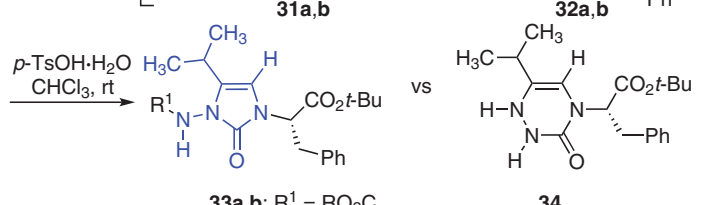

$$
\begin{aligned}
& \mathrm{Et}_{2} \mathrm{NH}, \mathrm{CH}_{2} \mathrm{Cl}_{2} \square \text { 33a, b: } \mathrm{R}^{1}=\mathrm{RO}_{2} \mathrm{C}
\end{aligned}
$$

Scheme 6 5-Substituted Nai peptide synthesis

Ordinary azodicarboxylates have been reacted with aldehydes and ketones using organocatalysis to afford $\alpha$-hydrazino carbonyl adducts. ${ }^{37,38}$ A route to 5-substituted Nai residues was conceived using proline-catalyzed conditions on azopeptides to provide aza-aspartate semialdehydes that cyclized to give the imidazol-2-one moiety. ${ }^{10}$ For example, $N$-Cbz-AzoGly-Phe-Ot-Bu (30a) was prepared by oxidation of azaGly counterpart 29a using $\mathrm{N}$-bromosuccinimide (NBS) and 2,6-lutidine in $\mathrm{CH}_{2} \mathrm{Cl}_{2}$ and then reacted with iso-valeraldehyde ( 4.0 equiv) in the presence of $\mathrm{L}$-proline ( 0.3 equiv) as the organocatalyst in $\mathrm{CH}_{2} \mathrm{Cl}_{2}$ (Scheme 6). ${ }^{10}$ An inseparable mixture of aza-aspartate semialdehyde 31a and hemiaminal 32a was obtained after chromatography and this was dehydrated using $p$-TsOH ( 0.3 equiv) to obtain $\mathrm{N}$-Cbz-5-(i-Pr)Nai-Phe-Ot-Bu (33a) in $85 \%$ overall yield from azapeptide 29a. ${ }^{10} \mathrm{~A}$ broad scope of 5-substituted Nai dipeptides 33a-o was subsequently prepared, having various aliphatic and aromatic $C$-terminal amino esters, by employing aldehydes bearing aliphatic, aromatic, carboxylate and protected amine functional groups (Figure 4). ${ }^{10}$

In principle, both the $\alpha$ - and $\beta$-nitrogen of the azopeptide may be attacked by the enamine intermediate to respectively provide after dehydration Nai dipeptide 33 or 6membered triazinone $\mathbf{3 4}$ (Scheme 6). The 5-membered ring was confirmed using ${ }^{1} \mathrm{H}\left({ }^{15} \mathrm{~N}\right)$ heteronuclear single quantum correlation (HSQC) NMR spectroscopy in $\mathrm{CDCl}_{3}$ on dipeptide 35, which was obtained after Fmoc removal from 33b using $\mathrm{Et}_{2} \mathrm{NH}$ in $\mathrm{CH}_{2} \mathrm{Cl}_{2} \cdot{ }^{10} \mathrm{~A}$ correlation between the nitrogen (55 ppm) and two-proton singlet (4.12 ppm) signified the presence of a primary rather than a secondary amine. Although the calculated vinyl proton chemical shifts were identical (6.39 ppm) for Nai 33 and triazinone 34, the corresponding carbon chemical shift values were significantly different: 101.7 and 97.3 ppm, respectively. Experimental analysis by ${ }^{13} \mathrm{C}$ NMR spectroscopy confirmed the imidazole2-one in all Nai analogues 33a-o, which exhibited vinylproton-bearing carbon chemical shifts of $101.7 \pm 2.1 \mathrm{ppm}$. In addition, X-ray crystallography of $\mathrm{N}$-Cbz-(5-Et)Nai-Phe$\mathrm{NH} i$ - $\mathrm{Pr}(\mathbf{3 6})$ substantiated the imidazole-2-one product. ${ }^{10}$

The enantiomeric purity of $\mathrm{Cbz}-(5-\mathrm{i}-\mathrm{Pr}) \mathrm{Nai}-\mathrm{Phe}-\mathrm{Ot}-\mathrm{Bu}$ (33a) was ascertained after preparation of diastereomeric peptides $(S, S)$ - and $(S, R)$-38 by ester solvolysis and coupling of acid 37 to D- and L-serine methyl ester using $N, N, N^{\prime}, N^{\prime}-$ tetramethyl-O-(1H-benzotriazol-1-yl)uronium hexafluorophosphate (HBTU) and $\mathrm{N}, \mathrm{N}$-diisopropylethylamine in THF (Scheme 7). ${ }^{10}$ Examination of the diastereotopic methyl ester singlets using ${ }^{1} \mathrm{H}$ NMR spectroscopy in $\mathrm{CDCl}_{3}$ and incremental doping of the minor isomer indicated a $>98: 2$

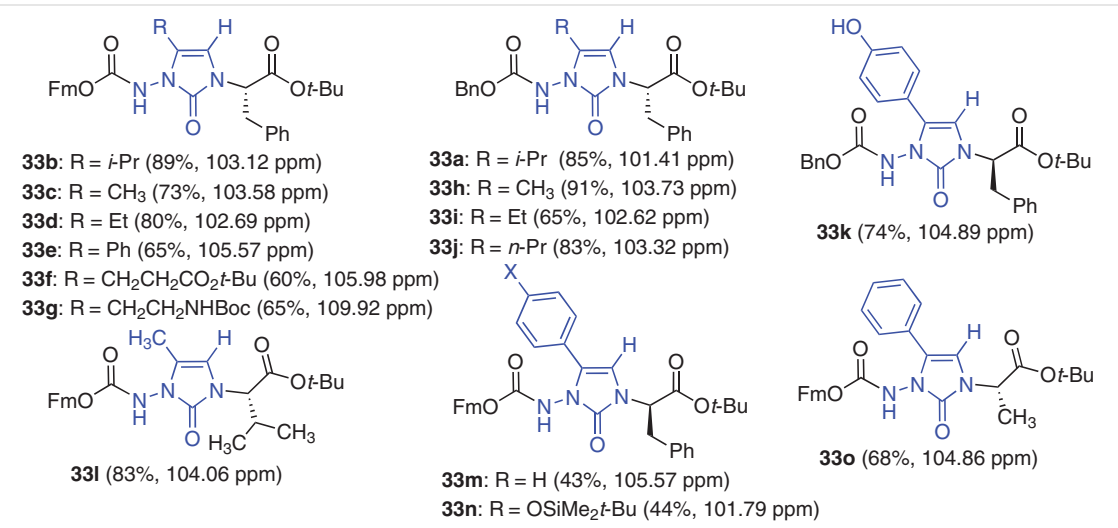

Figure 4 5-Substituted Nai scope and vinyl carbon NMR chemical shifts 
diastereomeric ratio and established that the 5-substituted Nai analogues were prepared in similarly high enantiomeric purity. ${ }^{10}$
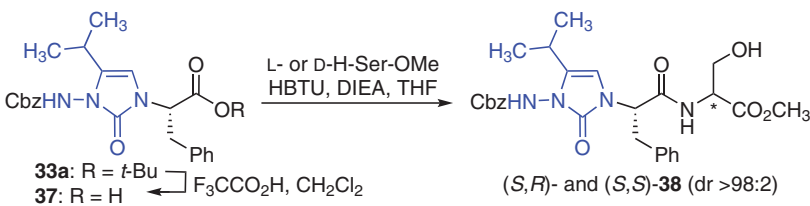

$(S, R)$ - and $(S, S)-38(\mathrm{dr}>98: 2)$

Scheme 7 Synthesis and purity of diastereomers $(S, S)$ - and $(S, R)-38$

\section{Conformational Analysis}

Crystals of model 4-substituted Nai peptides 13-15 were analyzed by X-ray diffraction. ${ }^{7,11}$ Two distinct conformations were commonly observed in the solid state for the 4-substituted Nai peptides. For example, p-MeOBz-(4Me)Nai-D-Phe-NHi-Pr (13) was observed to adopt both a type II' $\beta$-turn featuring a ten-membered hydrogen bond between the $i$ and $i+3$ residues (Figure 5, left) and an inverse $\gamma$-turn with a seven-membered hydrogen bond (Figure 5 , right). ${ }^{7,11}$ Rotation about the $\psi^{i+2}$ dihedral angle accounted primarily for the different conformers. ${ }^{7,11}$
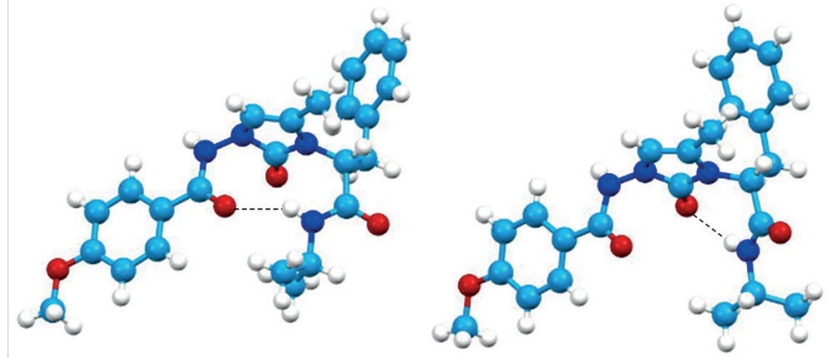

Figure 5 4-Methyl Nai model peptide 13 adopts type II' $\beta$-turn (left) and inverse $\gamma$-turn (right) conformers in the solid state. Dotted lines are presented in both $\mathrm{X}$-ray structures to infer hydrogen bonds in each turn geometry.

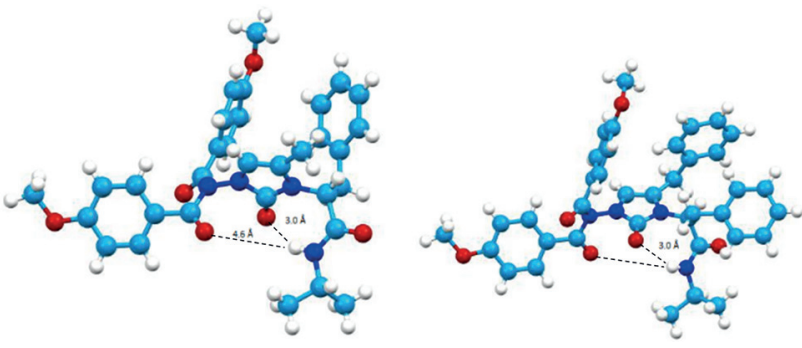

Figure 6 X-ray analyses of ( $p$-MeOBz) $)_{2}$ (4-Me)Nai-D-Phe-NHi-Pr (14, left) and ( $p-\mathrm{MeOBz})_{2}-(4-\mathrm{Bn}) \mathrm{Nai}-\mathrm{L}-\mathrm{Phe}-\mathrm{NHi}-\mathrm{Pr}(\mathbf{1 5}$, right) Dotted lines are presented in both $\mathrm{X}$-ray structures to infer hydrogen bonds in each turn geometry.

The effect of the substituent at the 4-position on the turn geometry was examined in the solid state by comparing X-ray crystallographic analyses of model peptides $\mathbf{1 4}$ and 15 with 4-methyl and 4-benzyl substituents, respectively (Figure 6 ). ${ }^{11}$ In peptides 14 and 15, a second $p$-methoxybenzoyl group exists compared to model peptide 13 . Comparing the two 4-methyl Nai analogues (i.e., 13 and 14), the second $p$-methoxybenzoyl group exerted about a $\pm 30^{\circ}$ rotation about the $\varphi^{i+1}$ dihedral angle and flattened the $\psi^{i+2}$ dihedral angle to a value of $180^{\circ}$. Peptide 14 retained the type II' $^{\prime} \beta$-turn and inverse $\gamma$-turn geometry (Table 1$){ }^{11}$ Switching from a 4-methyl to 4-benzyl substituent on the Nai ring had a significant influence on the $C$-terminal amino acid $\psi^{i+2}$ dihedral angel, which, due to the bulkier group, rotated away from the range of an ideal type II' $\beta$-turn and towards that of a $\gamma$-turn. The phenylalanine $\chi^{1}$ dihedral angle in model peptides 14 and $\mathbf{1 5}$ adopted gauche $\left(67.7^{\circ}\right)$ and trans $\left(-166.7^{\circ}\right)$ orientations, respectively. ${ }^{11}$

Table 1 Comparisons of Dihedral Angle Values for Ideal Turn Conformers to Those from Crystal Structures of Model 4-Substituted Nai Peptides 13-15 and Computational Analysis of 4,5-Disubstituted Nai Peptide 39

\begin{tabular}{|c|c|c|c|c|c|c|}
\hline Peptide & $\varphi^{i+1}$ & $\psi^{i+1}$ & $x^{i+1}$ & $\varphi^{i+2}$ & $\psi^{i+2}$ & $x^{i+2}$ \\
\hline ideal type II' $\beta$-turn & 60 & -120 & - & -80 & 0 & - \\
\hline ideal inverse $\gamma$-turn & - & - & - & -70 & 60 & - \\
\hline p-MeOBz-(4-Me)Nai-D-Phe-NHi-Pr (13) (Figure 5, left) & 58.9 & -153.3 & 165.9 & -69.1 & -4.6 & 54.6 \\
\hline p-MeOBz-(4-Me)Nai-D-Phe-NHi-Pr (13) (Figure 5, right) & 62.1 & -166.1 & 166.8 & -71.7 & 65.7 & 57.8 \\
\hline$(p-\mathrm{MeOBz})_{2}-(4-\mathrm{Me}) \mathrm{Nai}-\mathrm{D}-\mathrm{Phe}-\mathrm{NHi}-\mathrm{Pr}(\mathbf{1 4})$ & 88.3 & -177.3 & 166.5 & -70 & 31.2 & 67.7 \\
\hline$(p-\mathrm{MeOBz})_{2}-(4-\mathrm{Bn}) \mathrm{Nai}-\mathrm{L}-\mathrm{Phe}-\mathrm{NHi}-\mathrm{Pr}(\mathbf{1 5})$ & -91.4 & -174.9 & 165.1 & 79.2 & -63.6 & -166.7 \\
\hline p-MeOBz-(4-Me, 5-p-HOPh)Nai-D-Phe-NHi-Pr (39) & 48.6 & -143.7 & $\begin{array}{l}-41.1^{\mathrm{a}} \\
76.0^{\mathrm{b}}\end{array}$ & -62.4 & 33.6 & - \\
\hline
\end{tabular}

${ }^{\mathrm{a}} X(1)^{i+1}$.

${ }^{\mathrm{b}} X(2)^{i+1}$. 
Although related crystals of 4,5-disubstituted and 5substituted Nai model peptides have yet to be characterized, a computational analysis of $p$-MeOBz-(4-Me,5-p$\mathrm{HOPh}$ )Nai-D-Phe-NHi-Pr (39) was performed using starting coordinates from the crystal structure of 4-methyl counterpart 13. ${ }^{7,8}$ The 5 -position substituent of $\mathbf{3 9}$ was predicted to sit in the gauche $\chi^{1}$ orientation $\left(-41.1^{\circ}\right)$; moreover, the steric effects of $\mathrm{A}^{1,2}$ strain between the 4- and 5-substituents restricted $\chi^{2}$ rotation $\left(76.0^{\circ}\right)$. In the computational analysis, peptide 39 retained a type II' $\beta$-turn backbone geometry with the 5-aryl substituent of the (4-Me, 5-p-HOPh)Nai residue adopting a gauche-(-) orientation. ${ }^{8,39}$

\section{Biomedical Applications}

The utility of 5-substituted Nai residues has been reported in studies of two different classes of biologically relevant peptides. ${ }^{10,40}$ The almiramide peptides were studied because of their promising activity against trypanosomatid protozoan parasites by a mechanism that likely involves inhibition of glycosome function. ${ }^{41,42}$ Peptide ligands of the cluster of differentiation-36 receptor (CD36) were examined because of interest in their potential pleiotropic effects to modulate this scavenger receptor. ${ }^{43}$ With varying degrees of success, the examinations of these peptides using Nai residues were pursued to provide information about backbone and side-chain conformation..$^{10,40}$

5-Methyl Nai residues were introduced into almiramide B analogue 40 [ $\mathrm{HCC}\left(\mathrm{CH}_{2}\right)_{4} \mathrm{CO}-\mathrm{Val}-\mathrm{Val}-\mathrm{Val}-\mathrm{Ala}-\mathrm{Phe}-\mathrm{OH}$, which exhibited between $45-60 \mu \mathrm{M}$ potency against promastigotes of Leishmania infantum, and mutants resistant to the common antileishmanial agents (e.g., antimony, amphotericin B and miltefosine), as well as a selectivity index (macrophage toxicity/antiparasitic activity) of seven. ${ }^{40} \mathrm{Em}$ ploying a solid-phase synthesis approach, dipeptide $\mathbf{3 3 1}$ was converted into the corresponding acid 41, which was coupled respectively to $N^{\varepsilon}$-Val-Ala-Phe-O- and $N^{\varepsilon}$-Val-ValAla-Phe-O-2-chlorotrityl resins using diisopropyl carbodiimide (DIC) and hydroxybenzotriazole (HOBt) in N-meth- yl-2-pyrrolidone (NMP) to afford peptide resins $\mathbf{4 2}$ and 43. ${ }^{40}$ Peptide elongation was performed by Fmoc group removals and couplings to Fmoc-Val-OH and 6-heptynoic acid under similar conditions. After resin cleavage, purification using preparative high-performance liquid chromatography (HPLC) provided Nai peptides $\mathbf{4 4}$ and $\mathbf{4 5}$ (Scheme $8) .{ }^{40}$ Examination of Nai peptides $\mathbf{4 4}$ and $\mathbf{4 5}$ against the different Leishmania strains demonstrated that introduction of 5-methyl Nai residues for valine at the first and second residues of almiramide $B$ analogue $\mathbf{4 0}$ abolished completely antiparasitic activity. ${ }^{40}$

CD36 is implicated in a variety of biological processes including inflammation, angiogenesis, oxidized lipoprotein transport and autophagy. ${ }^{43}$ In the pursuit of CD36 ligands for biomedical applications, growth-hormone-releasing peptide-6 (GHRP-6, H-His-D-Trp-Ala-Trp-D-Phe-Lys- $\mathrm{NH}_{2}$ ) analogues have been pursued and shown to possess interesting modulatory activity but low selectivity. ${ }^{44}$ In contrast, CD36 selectivity has been achieved by employing azapeptide GHRP-6 analogues. ${ }^{43}$ Relatively high CD36 binding affinities, selectivity and promising utility have been exhibited by [azaPhe ${ }^{4}$ ]-GHRP-6 analogues. ${ }^{43-45}$ For example, [azaTyr $^{4}$ ]-GHRP-6 (46) has exhibited selective micromolar CD36 binding affinity and protective effects in models of macrophage-driven inflammation. ${ }^{43}$ In raw macrophages that were activated with the Toll-like receptor (TLR)-2 agonist $(R)$-fibroblast-stimulating lipopeptide (R-FSL-1), azapeptide 46 reduced nitric oxide production and diminished proinflammatory cytokine levels. ${ }^{45}$

5-Aryl Nai residues were introduced into [azaPhe ${ }^{4}$ GHRP-6 analogues using a solid-phase approach to study the biologically active backbone and side-chain topology of the azapeptide. ${ }^{10}$ 5-Aryl Nai dipeptide esters 33 were converted into the corresponding acids 47 , which were coupled to $N^{\varepsilon}$-(Boc)lysine Rink amide resin to provide Nai peptide resins 48 (Scheme 9). After removal of the Fmoc group, the sterically hindered and relatively non-nucleophilic semicarbazide was acylated using $N$-(Fmoc)alanyl chloride under microwave conditions. ${ }^{46}$ Subsequent elongation of peptide resin 49 and purification by preparative high-performance

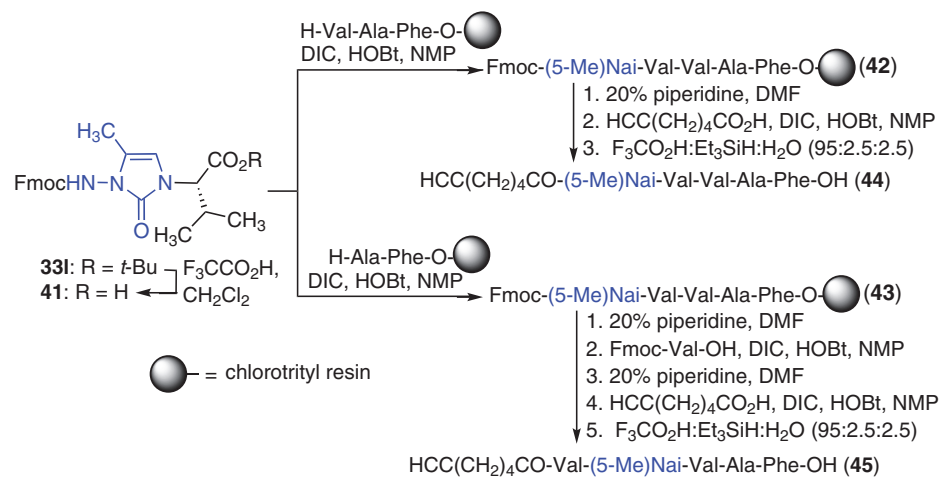

Scheme 8 (5-Me)Nai almiramide peptide analogue synthesis 
liquid chromatography (HPLC) provided [(5-Ph) and (5-pHOPh)Nai ${ }^{4}$-GHRP-6 analogues $\mathbf{5 0}$ and $\mathbf{5 1}$, which were evaluated for their CD36 binding affinity and their ability to attenuate nitric oxide (NO) overexpression during the proinflammatory response in comparison with [azaTyr $\left.{ }^{4}\right]$-GHRP-6 (46) as a positive control. ${ }^{10}$

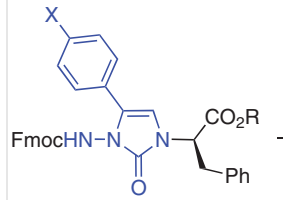

33m,n: $\mathrm{R}=t-\mathrm{Bu}{ }_{7} \mathrm{~F}_{3} \mathrm{CCO}_{2} \mathrm{H}$ 47m,n: $\mathrm{R}=\mathrm{H} \longleftarrow \mathrm{CH}_{2} \mathrm{Cl}_{2}$

1. Piperidine, DMF

2. Fmoc-D-Trp(Boc)OH, DIC, HOBt, DMF

3. Piperidine. DMF

4. Fmoc-His(Trt)-OH, DIC, HOBt, DMF

5. Piperidine, DMF

6. TFA/TES/ $\mathrm{H}_{2} \mathrm{O}$

$-\mathrm{NH}_{2}=$ Rink amide resin

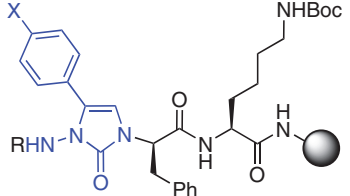

1) Piperidine, $D M F-48: R=F m o c$, $X=m, H ; n, O H$ $\mathrm{X}=\mathbf{m}, \mathrm{H} ; \mathbf{n}, \mathrm{OH}$

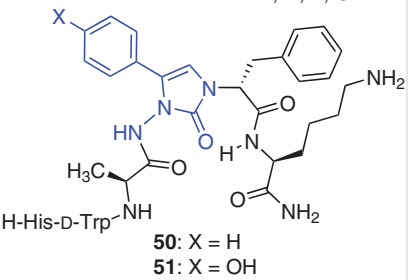

Scheme 9 Solid-phase synthesis of [(5-aryl)Nai $\left.{ }^{4}\right]-G H R P-6$ analogues 49: $\mathrm{R}=$ Fmoc-Ala

The CD36 binding affinities of [(5-Ph)Nai $\left.{ }^{4}\right]-G H R P-6(\mathbf{5 0})$ and $\left[(5-p-H O P h) N a i^{4}\right]-G H R P-6(51)$ were evaluated in a competition displacement study using the photoactivatable CD36 ligand [ $\left.{ }^{125} \mathrm{I}\right]-\mathrm{Bpa}-\mathrm{Ala}$ hexarelin (hexarelin $=[\mathrm{D}-(2-$ Me)Trp2 $]$-GHRP-6). ${ }^{43}$ In comparison with the relatively high binding affinities $\left(\mathrm{IC}_{50}\right)$ of hexarelin $(4.0 \mu \mathrm{M})$ and [azaTyr $\left.{ }^{4}\right]-$ GHRP-6 (46) $(3.1 \mu \mathrm{M}), 5$-aryl Nai analogues $\mathbf{5 0}$ and $\mathbf{5 1}$ engaged CD36 with approximately two- to three-fold lower binding affinity (8.1 and $10.0 \mu \mathrm{M}$, respectively).$^{10}$ Furthermore, 5-aryl Nai peptides $\mathbf{5 0}$ and $\mathbf{5 1}$ demonstrated comparable abilities as [azaTyr ${ }^{4}$-GHRP-6 (46) in reducing nitric oxide production in macrophages stimulated with the TLR2 agonist R-FSL- $1 .{ }^{10}$ Considering the similar binding affinities and anti-inflammatory activities exhibited by azapeptide 46 and 5-aryl Nai peptides 50 and 51, the semicarbazide moiety is likely positioned at the $i+1$ position in a $\beta$ turn with a gauche side-chain orientation in the active conformer. ${ }^{10}$

\section{Conclusion}

Different synthetic approaches have been developed in recent years for the creation of substituted Nai residues. Employing azaPra peptides, a series of 4-Nai analogues was synthesized by apparent exo-dig cyclization followed by olefin internalization. 4,5-Disubstituted Nai residues were prepared from the 4-substituted counterparts by routes featuring Pd-catalyzed arylation, Vilsmeier-Haack formylation and Mannich aminomethylation chemistry. 5-Substi- tuted Nai peptides were synthesized from azopeptide counterparts using proline-catalyzed reactions with aldehydes followed by acid-mediated cyclization of the resulting azaaspartate semialdehydes. Conformational analysis of the substituted Nai residues by X-ray crystallography and computational analysis demonstrated that model Nai peptides can adopt the central residues of $\beta$ - and $\gamma$-turn conformations. The 4- and 5-position substituents can mimic natural trans and gauche side-chain $\chi$-orientations. Substituted Nai residues have been incorporated into peptides using solidphase chemistry. In the context of CD36 modulators, the [(5-aryl)Nai $\left.{ }^{4}\right]-G H R P-6$ analogues exhibited relatively high binding affinity, ability to mitigate TLR-agonist-mediated inflammation and insight into the biologically active backbone and side-chain topology. Considering the effective synthetic methods for preparing analogues possessing a wide diversity of substituents, potential to mimic peptide turn conformations and validated utility in the form of biologically active CD36 modulators, Nai residues offer strong promise as tools for studying structure-activity relationships in peptide-based medicinal chemistry and for discerning active conformers in peptide science.

\section{Conflict of Interest}

The authors declare no conflict of interest.

\section{Funding Information}

This work was funded by the Natural Sciences and Engineering Research Council of Canada (NSERC), Discovery Research Project (Grant no. 04079), NSERC/Canadian Institutes of Health Research (CIHR), Collaborative Health Research Projects 'Treatment of Age-Related Macular Degeneration with CD36 Receptor Modulators' (Grant no. 315878) and 'Azacyclopeptide Modulators of Immuno-metabolism to Treat Age-Related Macular Degeneration' (Grant no. 163973), NuChem Therapeutics, Inc., Mperia Therapeutics, Inc. and the Fonds de Recherche Nature et Technologie Québec for the Centre in Green Chemistry and Catalysis (CCVC).

\section{Acknowledgment}

The authors acknowledge the assistance of members of the Université de Montréal facilities: Dr. A. Furtos, K. Venne, M.-C. Tang and K. Gilbert for mass spectrometry, F. Bélanger-Gariépy for X-ray diffractometry, G. Beaudry-Dubois and S. Bilodeau for NMR spectroscopy, and C. Camy and V.N.G. Lindsay for SFC analyses.

\section{References}

(1) Lubell, W. D. Preface, In Peptidomimetics I; Lubell, W. D., Ed.; Springer International Publishing: Cham, 2017, v-xiv.

(2) Robertson, N. S.; Spring, D. R. Molecules 2018, 23, 959.

(3) Qvit, N.; Rubin, S. J. S.; Urban, T. J.; Mochly-Rosen, D.; Gross, E. R. Drug Discovery Today 2017, 22, 454. 
(4) St-Cyr, D. J.; García-Ramos, Y.; Doan, N.-D.; Lubell, W. D. Aminolactam, $\mathrm{N}$-Aminoimidazolone, and $\mathrm{N}$-Aminoimdazolidinone Peptide Mimics, In Peptidomimetics I; Lubell, W. D., Ed.; Springer International Publishing: Cham, 2017, 125-175.

(5) Bucci, R.; Foschi, F.; Loro, C.; Erba, E.; Gelmi, M. L.; Pellegrino, S. Eur. J. Org. Chem. 2021, 2887.

(6) Jamieson, A. G.; Boutard, N.; Sabatino, D.; Lubell, W. D. Chem. Biol. Drug Des. 2013, 81, 148.

(7) Proulx, C.; Lubell, W. D. Org. Lett. 2012, 14, 4552.

(8) Poupart, J.; Doan, N.-D.; Berube, D.; Hamdane, Y.; Medena, C.; Lubell, W. D. Heterocycles 2019, 99, 279.

(9) Poupart, J.; Hamdane, Y.; Lubell, W. D. Can. J. Chem. 2020, 98, 278.

(10) Hamdane, Y.; Chauhan, P. S.; Vutla, S.; Mulumba, M.; Ong, H.; Lubell, W. D. Org. Lett. 2021, 23, 3491.

(11) Proulx, C.; Lubell, W. D. Biopolymers 2014, 102, 7.

(12) Dai, C.; Wang, F.; Zhang, D.; Xu, L.; Xia, X.; Zhang, J. Org. Lett. 2020, 22, 8475 .

(13) De Marco, R.; Zhao, J.; Greco, A.; Ioannone, S.; Gentilucci, L. J. Org. Chem. 2019, 84, 4992.

(14) Proulx, C.; Sabatino, D.; Hopewell, R.; Spiegel, J.; García Ramos, Y.; Lubell, W. D. Future Med. Chem. 2011, 3, 1139.

(15) Chingle, R.; Proulx, C.; Lubell, W. D. Acc. Chem. Res. 2017, 50, 1541.

(16) Freidinger, R. M. J. Med. Chem. 2003, 46, 5553.

(17) Ramachandran, G. N.; Sasisekharan, V. Conformation of Polypeptides and Proteins, In Advances in Protein Chemistry, Vol. 23; Anfinsen, C. B. Jr.; Anson, M. L.; Edsall, J. T.; Richards, F. M., Ed.; Academic Press: New York, 1968, 283-437.

(18) Hruby, V. J.; Li, G.; Haskell-Luevano, C.; Shenderovich, M. Pept. Sci. 1997, 43, 219.

(19) Cowell, S. M.; Lee, Y. S.; Cain, J. P.; Hruby, V. J. Curr. Med. Chem. 2004, 11, 2785.

(20) Ruiz-Gómez, G.; Tyndall, J. D. A.; Pfeiffer, B.; Abbenante, G.; Fairlie, D. P. Chem. Rev. 2010, 110, PR1.

(21) Koehler, K.; Sandstrom, W.; Cordes, E. H. J. Am. Chem. Soc. 1964, 86, 2413.

(22) Sabatino, D.; Proulx, C.; Klocek, S.; Bourguet, C. B.; Boeglin, D.; Ong, H.; Lubell, W. D. Org. Lett. 2009, 11, 3650.

(23) Buncel, E.; Menon, B. J. Am. Chem. Soc. 1977, 99, 4457.

(24) Reeve, W.; Erikson, C. M.; Aluotto, P. F. Can. J. Chem. 1979, 57, 2747.

(25) García-Ramos, Y.; Proulx, C.; Camy, C.; Lubell, W. D. Synthesis and Purification of Enantiomerically Pure N-Aminoimidazolin-2one Dipeptide, In Proceedings of the 32nd European Peptide Symposium; Kokotos, G.; Constantinou-Kokotou, V.; Matsoukas, J., Ed.; 32nd European Peptide Symposium: European Peptide Society, 2012, 366-367.
(26) Honzl, J.; Rudinger, J. Collect. Czech. Chem. Commun. 1961, 26, 2333.

(27) Lu, J.; Tan, X.; Chen, C. J. Am. Chem. Soc. 2007, 129, 7768.

(28) Su, W.; Weng, Y.; Jiang, L.; Yang, Y.; Zhao, L.; Chen, Z.; Li, Z.; Li, J. Org. Prep. Proced. Int. 2010, 42, 503.

(29) Arend, M.; Westermann, B.; Risch, N. Angew. Chem. Int. Ed. 1998, $37,1044$.

(30) Lindgren, B. O.; Nilsson, T. Acta Chem. Scand. 1973, 27, 888.

(31) Cramer, N.; Juretschke, J.; Laschat, S.; Baro, A.; Frey, W. Eur. J. Org. Chem. 2004, 1397.

(32) Chingle, R.; Lubell, W. D. Org. Lett. 2015, 17, 5400.

(33) Diels, O.; Blom, J. H.; Koll, W. Justus Liebigs Ann. Chem. 1925, 443, 242.

(34) Alder, K.; Pascher, F.; Schmitz, A. Ber. Dtsch. Chem. Ges. 1943, 76, 27.

(35) Chingle, R.; Ratni, S.; Claing, A.; Lubell, W. D. Biopolymers 2016 , 106, 235.

(36) Chingle, R.; Mulumba, M.; Chung, N. N.; Nguyen, T. M. D.; Ong, H.; Ballet, S.; Schiller, P. W.; Lubell, W. D. J. Org. Chem. 2019, 84, 6006.

(37) Kumaragurubaran, N.; Juhl, K.; Zhuang, W.; Bøgevig, A.; Jørgensen, K. A. J. Am. Chem. Soc. 2002, 124, 6254.

(38) List, B. J. Am. Chem. Soc. 2002, 124, 5656.

(39) Poupart, J.; Doan-Ngoc, D.; Lubell, W. D. 4,5-Disubstituted NAminoimdazol-2-one Mimics of Peptide Turn Backbone and Side Chain Conformation, In Proceedings of the 24th American Peptide Symposium, Srivastava V., Yudin A., Lebl M; 24th American Peptide Symposium: American Peptide Society, 2015, 272-273.

(40) Nguyen, A. M. T.; Brettell, S.; Douanne, N.; Duquette, C.; Corbeil, A.; Fajardo, E. F.; Olivier, M.; Fernandez-Prada, C.; Lubell, W. D. Molecules 2021, 26, 3606.

(41) Sanchez, L. M.; Lopez, D.; Vesely, B. A.; Della Togna, G.; Gerwick, W. H.; Kyle, D. E.; Linington, R. G. J. Med. Chem. 2010, 53, 4187.

(42) Sanchez, L. M.; Knudsen, G. M.; Helbig, C.; De Muylder, G.; Mascuch, S. M.; Mackey, Z. B.; Gerwick, L.; Clayton, C.; McKerrow, J. H.; Linington, R. G. J. Nat. Prod. 2013, 76, 630.

(43) Proulx, C.; Zhang, J.; Sabatino, D.; Chemtob, S.; Ong, H.; Lubell, W. D. Biomedicines 2020, 8, 241.

(44) Proulx, C.; Picard, E.; Boeglin, D.; Pohankova, P.; Chemtob, S.; Ong, H.; Lubell, W. D. J. Med. Chem. 2012, 55, 6502.

(45) Chignen Possi, K.; Mulumba, M.; Omri, S.; Garcia-Ramos, Y.; Tahiri, H.; Chemtob, S.; Ong, H.; Lubell, W. D. J. Med. Chem. 2017, 60, 9263.

(46) Freeman, N. S.; Tal-Gan, Y.; Klein, S.; Levitzki, A.; Gilon, C. J. Org. Chem. 2011, 76, 3078. 